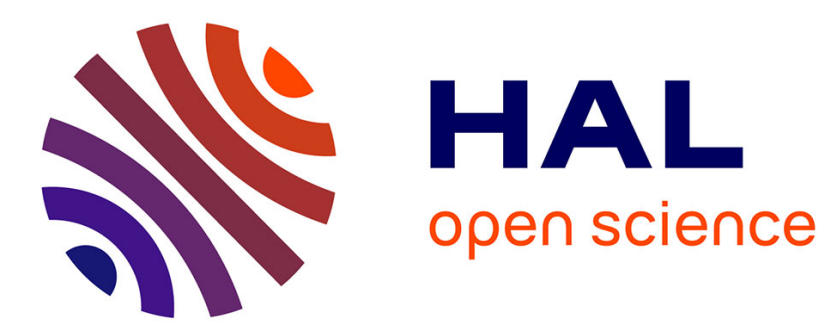

\title{
MICROSCOPY : A MEANS TO STUDY SURFACE STRUCTURES
}

K. Takayanagi, Y. Tanishiro, K. Murooka

\section{To cite this version:}

K. Takayanagi, Y. Tanishiro, K. Murooka. MICROSCOPY: A MEANS TO STUDY SURFACE STRUCTURES. Journal de Physique Colloques, 1987, 48 (C6), pp.C6-525-C6-530. 10.1051/jphyscol:1987686 . jpa-00226894

\section{HAL Id: jpa-00226894 https://hal.science/jpa-00226894}

Submitted on 1 Jan 1987

HAL is a multi-disciplinary open access archive for the deposit and dissemination of scientific research documents, whether they are published or not. The documents may come from teaching and research institutions in France or abroad, or from public or private research centers.
L'archive ouverte pluridisciplinaire HAL, est destinée au dépôt et à la diffusion de documents scientifiques de niveau recherche, publiés ou non, émanant des établissements d'enseignement et de recherche français ou étrangers, des laboratoires publics ou privés. 


\title{
MICROSCOPY : A MEANS TO STUDY SURFACE STRUCTURES
}

\author{
K. Takayanagi, Y. Tanishiro and K. Murooka \\ Department of Physics, Tokyo Institute of Technology, Oh-okayama, \\ Meguro-ku, Tokyo 152, Japan
}

High-resolution UHV electron microscopy of surfaces and clusters in transmission (TEM) mode has revealed dynamic behavior of surfaces and clusters at atomic-level resolution using videotape recording. Validity and limitation of the electron microscopy are discussed and future instrumental developments for atomic level structure analysis, combination of EM and FIM, is suggested.

\section{Introduction}

Atomic details of surface structures are of great value for understanding the phase transition, film growth and catalytic reactions on surfaces and clusters. To study surface structures, field ion microscopy (FIM), scanning tunneling microscopy (STM) and high-resolution electron microscopy (HREM) are used increasingly.

In transmission (TEM) and reflection (REM) electron microscopy, surface structures have been seen at monolayer or at atomic-level resolution. Atomic surface steps have been observed first by brightand dark-field imaging[1,2], and atomic-level details, by profile imaging[3-6] and by plan-view imaging[7]. Similarly to TEM, observations of surface steps were aimed by REM soon after the innovation of electron microscopes[8], although the observation has become possible after the innovation of ultra-high vacuum(UHV) electron microscopy[9].

UHV electron microscopy under $10^{-8}$ Torr has proved to be powerful in REM and TEM modes for studies of clean surfaces and film growth processes[10-13], which have not been observed by electron microscopes of ordinary vacuum of $10^{-6}$ Torr. These woks made by a electron microscope of $100 \mathrm{kV}$ acceleration voltage (modified JEOL $100 \mathrm{~B}$ ) have been extended recently by developing a new high-resolution electron microscope (modified JEOL 2000FXV)[14-16]. In this paper, recent observations on surfaces done by this new microscope are shown with some new results.

The electron microscope is operated under $10^{-10}$ Torr and has insitu deposition facilities. The point-to-point resolution is $0.22 \mathrm{~nm}$ at $200 \mathrm{kV}$ acceleration, being designed to resolve (111) lattice fringes for most of metals and semiconductors. 
2. Experimental

Using the new high-resolution electron microscope, following observations have been done on structures and dynamic behaviors of

1) Au atom clusters of single to several atoms,

2) reconstructed surface structures on $\mathrm{Au}(001),(110)$ and (111)

surfaces,

3) Si(111)7 87 reconstructed surfaces and phase transition to " $1 \times 1$ " at $830^{\circ} \mathrm{C}$, and

4) thin metal overlayers on Si(111) surface.

In these works, clean well-defined surfaces were made by deposition to a lateral surface of graphitized carbon film for the observation 1) and 2), and of bulk Si surface for the observation 4). Growth processes of atom clusters and metal overlayers on Si surface were recorded on videotapes using TV camera. To improve the images which are recorded every $1 / 30$ sec on video tapes, recursive filtering was done using a image processor (image sigma-II). A part of the results on topic 1) and on 2) are shown. Field desorption experiment of tungsten tips were done using the uHV electron microscope of $100 \mathrm{kV}$ acceleration.

\section{Results and Discussion}

Figures from $1(\mathrm{a})$ to $1(\mathrm{~h})$ are reproduced from a videotape of gold atomic clusters growing on graphitized carbon. Each dark dot is an image of a few atoms aligned in a row parallel to the incident electron beam, and the fringes appearing at the lower half of each micrograph are lattice fringes of the graphitized carbon which was crystallized from amorphous carbon by strong electron dose given intentionally. The electron beam intensity during the observations was $10-30 \mathrm{~A} / \mathrm{cm}^{2}$.

The above observation have revealed for the first time structures and dynamics of atom clusters which consist of atoms less than 100 . Spectacular observations have been made by Iijima and Ichihashi[5] for small gold clusters. In their report, dynamic behavior of small atom clusters has been stressed from the observation that a Au cluster with 500 atoms is changed from multiply twinned(MTP) structure to normal f.c.c. structure on $\mathrm{SiO}_{2}$ substrate. In. our observation, no such drastic change of the structure was not observed for such large clusters, but most of Au clusters of such sizes had MTP structure and showed only orientational fluctuation. The drastic change of the structure observed by IiJima and Ichihashi, then, is due to strong electron beam irradiation of $200 \mathrm{~A} / \mathrm{cm}^{2}$, which is 10 times stronger than ours.

In the growth process in Fig.1, a cluster of single $\operatorname{dot}$ in (a) was disappeared soon after, while a cluster of double dots in (b) was grown further in (b), (c) and so on. Images of clusters in these figures were selected from hundreds of video frames and have regular arrangements of dots rather than the other frames. From the arrangements of the dots, we surmise three dimensional structures of the clusters ( the electron microscope images correspond to the cluster on an imaging plane perpendicular to the incident electron beam). The cluster in (h) is an icosahedral cluster ( or a part of an icosahedral cluster, consisting of 147 atoms. The number of atoms in 

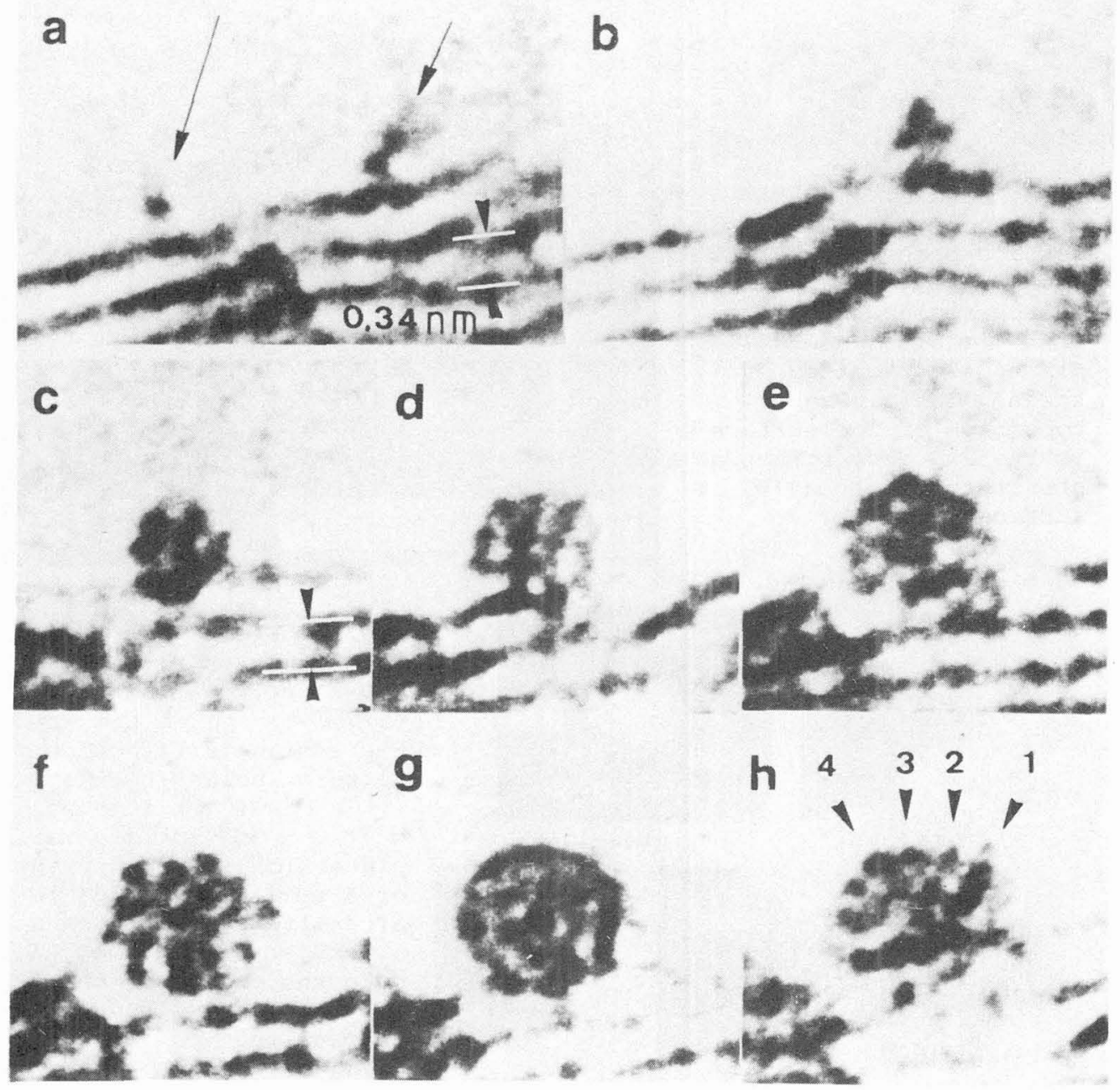

Fig. 1 growth process of gold clusters on graphitized cabon film. Each dark dots is an image of a few atoms aligned along the incident beam direction. Note arrangements of dots. The fringes at the lower part of each figure are lattice fringes of the graphitized carbon[see ref.16].

Fig. 2 Atomic arrangement of an icosahedral cluster with 55 atoms. Compare this model with the image in Fig.1 (g).

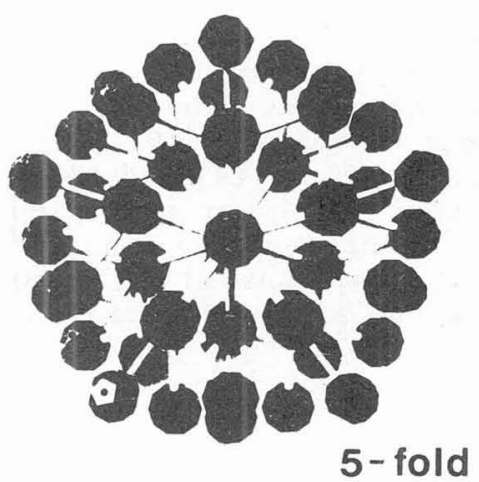


Fig. 3 Profile image of an gold particle. The right hand side is the (111) pole. the (111) lattice planes normal to the pole are resolved. On the region extended from the pole, the (111) planes are facetted every three. The zig-zag topograph of the surface is the $2 \times 1$ reconstructed structure of the (110) surface [18].

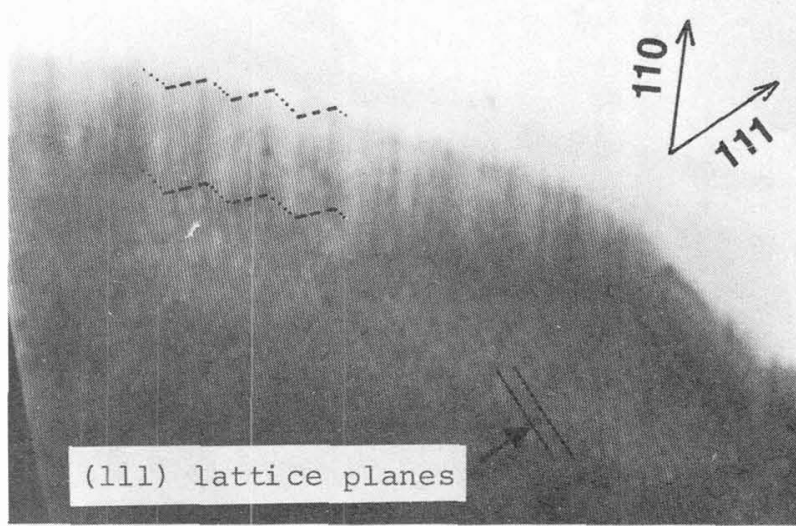

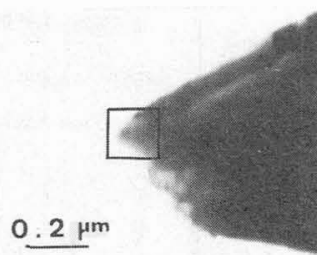

(a)

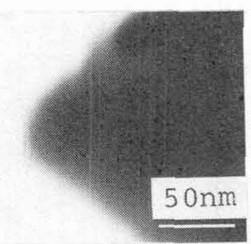

(d)

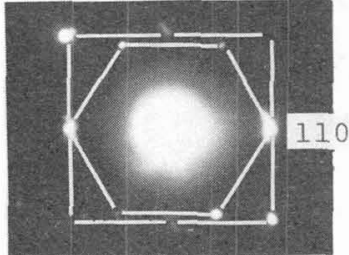

(b)

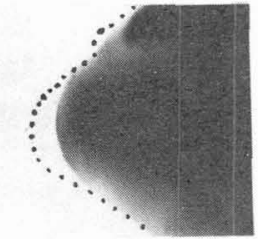

(c)

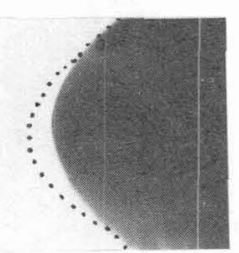

(e)
Fig. 4 Field evaporation of a tungsten tip in a UHV electron microscope. (a) topograph of the $W$ tip and (b) diffraction pattern indicating that (110) and (001) domains with a (110) interfacial plane. (c) enlarged image of a part of (a), (d) after field desorption at $5.0 \mathrm{kV}$ and (e) at $7.0 \mathrm{kV}$. Note the change of the tip radius by field desorption.
Fig. 5 Illustration of an arrangement around the objective pole piece for EM and FIM observation. The tip is (6) at biased voltage, (5) is for extraction. (4) and (7) are the upper and lower pole pieces, respectively. (3) and (8) are cryogenic shield to improve the vacuum around the tip.

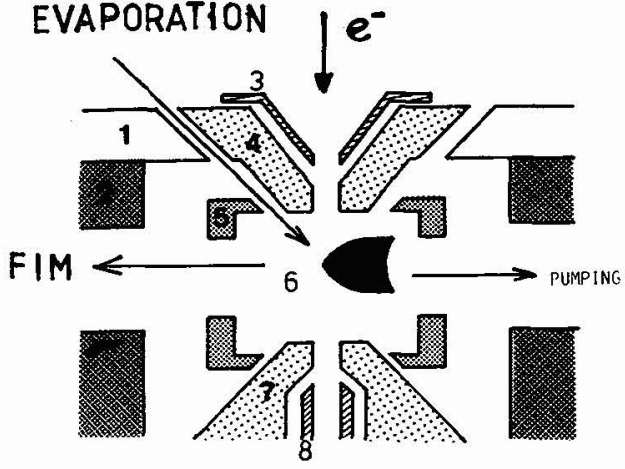


each atom row expected from the model structure is indicated in the figure, which agrees well with the order of the contrast of the dots. The cluster in Fig.(g) is considered to be an icosahedral cluster with 55 atoms. As schematically shown in Fig.2, the model structure explains the electron microscope image. Structures of clusters in Figs. (f) - (b) are difficult to deduce, except that local arrangements of the dots are well explained by various stacking of an unit of tetragonal cluster, e.g. two tetragonal clusters in twin relation.

Thus, high-resolution electron microscopy can reveal structures and dynamics of atomic clusters and even single atom as reported in ref.17. The images, however, give only two dimensional information directly. For the atomic-level surface study, supplemental information about the number and mass of clusters is needed further.

Figure 3 shows a profile image of Au particle grown on a lateral surface of graphitized carbon. The image shows surface topographs of the particle, similar to tips used for FIM study. The curved lines on the lower part of the figure are atomic steps around the (111) pole. The surface of zigzag topographs extended towards the left of the figure has (110) orientation. The surface consists of (111) facets and dark lines (short bars) seen on each facet are [110] atomic rows. We see three atomic rows on each facet. This indicates that the surface is reconstructed to $2 \times 1$. It is interesting that we can see three dimensional topographs in the image in Fig.3, which was obtained by the incident beam inclined to the [ $\overline{1} 10]$ atomic row. This observation suggests a possibility of TEM studies on surface structures using a sharp tip similar to FIM study.

Figure 4 shows a preliminary study of UHV electron microscope observation of a tungsten tip. This tip was electrochemically etched by $2-\mathrm{N}$ NaOH solution. In the microscope, the surface of the tip was cleaned by field evaporation. After applying $5.0 \mathrm{kV}$ to the specimen, contamination covering the tip was taken off and the tip was rounded in Fig.(c). After applying $7.0 \mathrm{kV}$ in Fig.(d), the tip radius was changed from $36 \mathrm{~nm}$ to $46 \mathrm{~nm}$. The UHV microscope used has only low resolution and atomic details were not seen. This study suggests a combination of EM and FIM (atom probe) would be powerful for analyses of surfaces and clusters at atomic level. In this connection, a combination of EM and STM is also powerful for solving problems in surface science.

\section{Summary}

High-resolution UHV electron microscopy is useful for atomiclevel studies of surfaces and clusters. Many applications can be made to surface problems by developing in-situ facilities such as deposition system and by combination with FIM (atom probe) and STM.

The authors thank sincerely Prof. O.Nishikawa for valuable discussions on field ion microscopy, and also K.Ohi, Y.Kondo, H.Hirano, Y.Ishibashi, H.Kobayashi and Y.Harada for the construction of the high-resolution UHV electron microscope. This work has been supported by a Grant-in-Aid for Scientific Research from the Ministry of Education, Science and Culture (Grant No. 61850118). 
References

1) D.Cherns, Philos. Mag. 30, 549(1974).

2) K.Kambe and G.Lehmpfuhl, Optik 42, 187(1975).

3 ) I.D.Marks and D.J.Smith, Nature 303, 316(1983).

4) J.O.Bovin, Nature 317, 47(1985).

5) S.Iijima and T.Ichihashi, Phys. Rev. B56, 616(1986).

6) T.Hasegawa, N.Ikarashi, K.Kobayashi, K.Takayanagi and K.Yagi, Proc. 11 th Int. Cong. on Electron Microscopy, Kyoto, 1986,(Ed. T.Imura, S.Maruse and T.Suzuki, The Jpn. Society of Electron Microscopy) p. 1345 .

7) K.Takayanagi, K.Kobayashi, Y.Kodaira, Y.Yokoyama and K.Yagi, Proc. 8 th Int. Conf. on HVEM, Berkeley, 1983,(Ed. R.M.Fisher, R.Gronsky and K.H.Westmacott, National Technical Information Service) p.47.

8) E.Ruska, Z.Phys. 83, 492(1933).

9) N.Osakabe, Y.Tanishiro, K.Yagi and G.Honjo, Surface Sci. 97, $393(1980)$.

10) K.Takayanagi, K.Yagi, K.Kobayashi and G.Honjo, J. Phys, E11, $441(1978)$.

11) G.Honjo and K.Yagi, Current Topics in Materials Science, 1980,(Ed. Kaldis, North Holland) p.196.

12) K.Yagi, K.Takayanagi and G.Honjo, Crystals, vol.7, 1982,(Ed. H.C.Freyhardt, Springer Verlag, Berlin) p.47.

13) K.Takayanagi, U1tramicroscopy, 8, 145(1982).

14) K.Takayanagi, Y.Tanishiro, K.Kobayashi, N.Yamamoto, K.Yagi, K.Ohi, Y.Kondo, H.Hirano, Y.Ishibashi, H.Kobayashi and Y.Harada, Proc. 11 th Int. Cong. on Electron Microscopy, Kyoto, 1986, (Ed. T.Imura, S.Maruse and T.Suzuki, The Jpn. of Electron Microscopy) 9.1337.

15) K.Takayanagi, Y.Tanishiro, K.Kobayashi, K.Akiyama and K.Yagi, Jpn. J. Appl. Phys. 26, L957(1987).

16) K.Takayanagi, Proceeding of APSSS, Shanghai, 1987, to be published.

17) K.Takayanagi et al., Phys Rev. Letter, submitted.

18) Y.Kondo et al., in preparation. 